\title{
Molecular Structure of Butanediol Isomers in Gas and Liquid States: Combination of DFT Calculations and Infrared Spectroscopy Studies
}

\author{
A. J. Lopes Jesus, Mário T. S. Rosado, M. Luísa P. Leitão,* and José S. Redinha \\ Departamento de Química, Universidade de Coimbra, 3004-535 Coimbra, Portugal
}

Received: October 3, 2002; In Final Form: December 12, 2002

\begin{abstract}
Density functional theory (Becke3LYP/6-311++ $\mathrm{G}^{* *}$ ) conformational analysis was carried out for all positional butanediol isomers. Taking into account the relative populations of the most stable conformers at $298.15 \mathrm{~K}$, the weighted mean enthalpies of each butanediol isomer in the gas state were computed. Combining these results with the experimental values for the enthalpies of vaporization at $298.15 \mathrm{~K}$, an estimate of the enthalpy of each of the butanediol isomers in the liquid state was obtained and discussed. The insight into the structural changes at the molecular level from the isolated molecule to the condensed state was improved by an infrared spectroscopy study in the $\mathrm{OH}$ stretching region, which was carried out for a wide range of concentrations of carbon tetrachloride solutions and pure liquids. The spectroscopic studies essentially confirmed the results derived from the combination of the computational and calorimetric studies.
\end{abstract}

\section{Introduction}

Butanediol isomers are compounds with numerous applications in biochemical research, namely in cryopreservation of living organs. ${ }^{1-4}$ In aqueous solution, they are regarded as model compounds of biomolecules having polar as well as nonpolar groups. The knowledge of the properties of these compounds in the various aggregation states of matter is essential to understand their behavior.

Despite their relative small size, the isolated butanediol molecules have not been extensively studied by theoretical calculations in the past. In fact, most of them used less expensive computational methods such as molecular mechanics ${ }^{5,6}$ and semiempirical calculations. ${ }^{7,8}$ To our knowledge, the only ab initio studies on isolated molecules of butanediols were published by Szarecka et al. ${ }^{8}$ on $(R, R)-2,3$-butanediol using relatively modest basis sets (STO-3G, 3-21G, and 6-31G*) and by Polavarapu et al. ${ }^{9}$ on the same molecule using DFT calculations with the B3LYP functional and the $6-31 \mathrm{G}^{*}$ basis set. The few available results mentioned above suggest the presence of an intramolecular hydrogen bond as the key stabilizing factor in the gas state structure of butanediols. General agreement with this trend was also obtained from experimental data, namely infrared spectroscopy, ${ }^{10-12}$ microwave spectroscopy, ${ }^{13}$ and electron diffraction. ${ }^{6}$

As part of a more extensive program of study, we recently determined the standard enthalpy of vaporization, $\Delta H^{\circ}$ vap, of 1,2-butanediol (1,2-BD), 1,3-butanediol (1,3-BD), 1,4-butanediol (1,4-BD), and 2,3-butanediol (2,3-BD). ${ }^{14}$ This property is very useful because it is called whenever one needs to report a measure performed on the liquid to a standard gas state. For example, to determine the enthalpy of solvation from the enthalpy of solution of a compound in liquid state, the enthalpy of vaporization is required. As will be shown in the present study, this thermodynamic property is also valuable to estimate the enthalpy of the compound in liquid state, provided its

* To whom all correspondence should be addressed. E-mail: mlleitao@ci.uc.pt. enthalpy in the gas state is known. This strategy allows overcoming the difficulties arising for performing computational calculations of a rather complicated and uncertain structure as that of the liquid.

General comparisons between the gas and the liquid enthalpies of butanediols were previously made by Benson's group additivity methods. ${ }^{15}$ These methods are used to calculate enthalpies of formation from individual molecular fragments contributions, which are themselves the results of correlations derived from scarce and mostly rather old and inaccurate experimental determinations of enthalpies of vaporization and enthalpies of combustion. They also do not take into account any conformational features within the specific studied molecules. Thus, we feel that the liquid enthalpy values derived from the combination of high-level, multiconformer theoretical calculations and accurate direct experimental determination of enthalpies of vaporization, performed on the specific molecules studied and not resulting from general statistics, are of better quality.

In this paper, the energies of the most stable conformers of each butanediol were determined by density functional theory calculations (DFT). From the values found for the energy and for the relative populations of the conformers, the mean energy and enthalpy of each isomer in the gas state at $298.15 \mathrm{~K}$ were obtained. Combining the values found for the enthalpy in the gas state with our results for the enthalpy of vaporization, ${ }^{14}$ the enthalpy of each isomer in the liquid state was evaluated. Therefore, both the gas and the liquid states of butanediols are targets of the present study.

Because of the importance of the hydrogen bonding as a determinant structural feature of butanediols in gas and liquid state, a vibrational spectroscopy study in the hydroxyl stretching region was performed. This study is a valuable complement of the computational and calorimetric determinations. The solution spectra in a relatively wide range of concentrations in an inert solvent $\left(\mathrm{CCl}_{4}\right)$ and of pure liquids allow the characterization of the hydrogen bonding for isolated molecules and for different aggregation states up to the liquid. 


\section{Computational Methods}

Butanediol isomers are very flexible molecules since they have several relevant dihedrals leading to many possible local minima. Thus, the determination of the low-energy conformations using a systematic search method is computationally very expensive. Hence, for each butanediol isomer, a molecular mechanics conformational search model employing random generation and subsequent full minimization of every conformational parameter was used in order to derive a reasonable sampling of the low-energy conformations. These calculations were carried out with the Cerius2 (version 3.5) molecular modeling package ${ }^{16}$ running on an SGI O2/RS5000 workstation. All the molecular mechanics calculations were performed using the CFF91 force field of Hagler et al. ${ }^{17,18}$

The structure of the low-energy conformers (less than $10 \mathrm{~kJ}$ $\mathrm{mol}^{-1}$ above the global minimum, as this difference corresponds to a population ratio of ca. $2 \%$ ), as obtained from the previously described molecular mechanics calculations, was fully optimized by density functional theory ${ }^{19,20}$ (DFT) calculations using the Becke3LYP functional ${ }^{21-23}$ and the $6-311++\mathrm{G}^{* *}$ basis set. The convergence criteria were defined according to the Gaussian standard values. Additionally, the vibrational frequencies of each resulting conformation were checked out to ensure that they correspond to true minima and not to any other type of stationary point on the potential energy surface. The DFT calculations were performed using the GAUSSIAN 98 program package, ${ }^{24}$ running in a PC equipped with an AMD Athlon (900 MHz) processor.

The geometry optimizations by ab initio and DFT methods only provide the minimized electronic energy $\left(E_{\text {elec }}\right)$ of a molecular system. To obtain the total energy $\left(E_{\text {total }}\right)$ at 298.15 $\mathrm{K}$ from the value given by $E_{\text {elec}}$, several corrections should be included. First, the zero-point vibrational energy (ZPE) must be added to the electronic energy, giving the energy at absolute zero temperature $\left(E_{0}\right)$. Second, one must add the temperaturedependent vibrational $\left(E_{\mathrm{vib}}\right)$, rotational $\left(E_{\mathrm{rot}}\right)$, and translational $\left(E_{\text {trans }}\right)$ energies. Summarizing

$$
E_{\text {total }}=E_{\text {elec }}+\mathrm{ZPE}+E_{\mathrm{vib}}+E_{\text {rot }}+E_{\text {trans }}
$$

Then, for each butanediol isomer, the low-energy conformers were weighed by their Boltzmann populations and then used to calculate the weighted mean energy and enthalpy of each one of the butanediol isomers in the gas state.

\section{Results and Discussion}

Conformational Analysis in the Gas State. The conformations are defined according to the following rules: trans $\left(180 \pm 30^{\circ}\right)$, gauche clockwise $\left(60 \pm 30^{\circ}\right)$, and gauche anticlockwise $\left(-60 \pm 30^{\circ}\right)$, abbreviated $\mathrm{t}$ or $\mathrm{T}, \mathrm{g}$ or $\mathrm{G}$, and $\mathrm{g}^{\prime}$ or $\mathrm{G}^{\prime}$, respectively. The capital letters refer to the backbone dihedrals while the minuscule ones refer to the dihedrals which contain the $\mathrm{OH}$ groups. The carbon atoms are numbered following the usual convention; the oxygen atoms keep the number of the carbon to which it is attached and the hydrogen that is assigned to the respective oxygen atom. In Table 1, we summarize the conformational nomenclature used.

Table 2 characterizes the conformers found for each butanediol isomer, according to the scheme described above. Relevant dihedral angles, values of the relative energy $\left(\Delta E_{0}\right)$, total energy at $298.15 \mathrm{~K}\left(E_{\text {total }}\right)$, and dipole moment $(\mu)$ are also given in this table. The relative populations $(P)$ were calculated according to the Boltzmann distribution based on the zero temperature energy and taking into account the degeneracy degree of each
TABLE 1: Conformational Nomenclature for the Conformations of the Butanediol Isomers

\begin{tabular}{ccccc}
\hline & \multicolumn{4}{c}{ dihedral angle } \\
\cline { 2 - 5 } letter & $(R)-1,2-\mathrm{BD}^{a}$ & $(R)-1,3-\mathrm{BD}^{a}$ & $1,4-\mathrm{BD}$ & $2,3-\mathrm{BD}^{a, b}$ \\
\hline 1st & $\mathrm{H}_{1} \mathrm{O}_{1} \mathrm{C}_{1} \mathrm{C}_{2}$ & $\mathrm{H}_{1} \mathrm{O}_{1} \mathrm{C}_{1} \mathrm{C}_{2}$ & $\mathrm{H}_{1} \mathrm{O}_{1} \mathrm{C}_{1} \mathrm{C}_{2}$ & $\mathrm{H}_{2} \mathrm{O}_{2} \mathrm{C}_{2} \mathrm{C}_{3}$ \\
2nd & $\mathrm{O}_{1} \mathrm{C}_{1} \mathrm{C}_{2} \mathrm{O}_{2}$ & $\mathrm{O}_{1} \mathrm{C}_{1} \mathrm{C}_{2} \mathrm{C}_{3}$ & $\mathrm{O}_{1} \mathrm{C}_{1} \mathrm{C}_{2} \mathrm{C}_{3}$ & $\mathrm{O}_{2} \mathrm{C}_{2} \mathrm{C}_{3} \mathrm{O}_{3}$ \\
3rd & $\mathrm{C}_{1} \mathrm{C}_{2} \mathrm{C}_{3} \mathrm{C}_{4}$ & $\mathrm{C}_{1} \mathrm{C}_{2} \mathrm{C}_{3} \mathrm{O}_{3}$ & $\mathrm{C}_{1} \mathrm{C}_{2} \mathrm{C}_{3} \mathrm{C}_{4}$ & $\mathrm{C}_{2} \mathrm{C}_{3} \mathrm{O}_{3} \mathrm{H}_{3}$ \\
4th & $\mathrm{C}_{1} \mathrm{C}_{2} \mathrm{O}_{2} \mathrm{H}_{2}$ & $\mathrm{C}_{2} \mathrm{C}_{3} \mathrm{O}_{3} \mathrm{H}_{3}$ & $\mathrm{C}_{2} \mathrm{C}_{3} \mathrm{C}_{4} \mathrm{O}_{4}$ & \\
5th & & & $\mathrm{C}_{3} \mathrm{C}_{4} \mathrm{O}_{4} \mathrm{H}_{4}$ &
\end{tabular}

${ }^{a} R$ and $S$ refer to the nature of chiral centers in stereoisomers. ${ }^{b}$ This nomenclature is valid for both $(R, S)$ - and $(S, S)$-configurations.

conformer. The geometries of the lowest energy conformers of each butanediol isomer are displayed in Figure 1.

As can be seen, the most stable conformers are stabilized by an intramolecular hydrogen bond between the hydroxyl groups. The bond is evidenced by an increase of the $\mathrm{O}-\mathrm{H}$ bond length and a decrease of the $\mathrm{O} \cdots \mathrm{H}$ distance. Owing to the highly directional nature of the hydrogen bond, the $\mathrm{O}-\mathrm{H} \cdots \mathrm{O}$ bond angle is another structural feature to be included in the discussion of the bond strength. Despite the linear preference of the bond $\left(\mathrm{O}-\mathrm{H} \cdots \mathrm{O}\right.$ close to $\left.180^{\circ}\right)$, a large range of values can be observed for this angle at some expense of the bond strength.

In Table 3 are displayed the values calculated for structural characteristics related with hydrogen-bonding manifestations for the lowest energy conformers of each isomer. From these data one concludes that the intramolecular hydrogen bond is the dominant stabilizing factor in the lowest energy conformers. Among the conformers presented in Figure 1, the one that presents the highest value for the $\mathrm{O} \cdots \mathrm{H}$ distance is $(R, S)-2,3$ BD. Nevertheless, this figure is below the limit commonly adopted as criteria for the existence of hydrogen bonding $(2.5 \AA) .{ }^{25,26}$ The $\mathrm{O}-\mathrm{H}$ length for this conformer is also above the value obtained for conformers without an intramolecular hydrogen bond (ca. $96.2 \mathrm{pm}$ ). The deviation of the $\mathrm{O}-\mathrm{H} \cdots \mathrm{O}$ angle from $180^{\circ}$ contributes to a considerable weakening of the intramolecular hydrogen bond. According to the values given in Table 3, within the isomers for which the hydroxyl groups are attached to vicinal carbon atoms, the strength of the intramolecular hydrogen bond increases from $(R, S)-2,3-\mathrm{BD}$ to $(R)-1,2-\mathrm{BD}$ and this to $(S, S)-2,3-\mathrm{BD}$, although the differences between these structural parameters are similar. A strengthening of this interaction is observed from vicinal diols to $(R)-1,3-\mathrm{BD}$ and from this to $1,4-\mathrm{BD}$.

As a consequence of the formation of intramolecular hydrogen bonds, the lowest energy conformers of all isomers (see Figure 1) adopt a five (1,2-BD and 2,3-BD) to seven-membered (1,4$\mathrm{BD})$ ringlike geometry. In fact, the overall population of hydrogen-bonded conformers at $298.15 \mathrm{~K}$ is always greater than about $90 \%$. Another common trend is the orientation of the free hydroxyl group, which tends to be preferentially trans relative to its adjacent $\mathrm{C}-\mathrm{C}$ bond in the heavy atom skeleton (see Figure 1).

The most stable conformers of the two vicinal butanediols adopt a gauche arrangement around the OCCO dihedral, enabling the establishment of the hydrogen bond between the hydroxyl groups. This conformational trend has also been observed in previous computational studies regarding smaller vicinal diols ${ }^{27,28}$ and 2,3-BD. ${ }^{8,9}$ For the most populated conformational states of $(R)-1,2-\mathrm{BD}$, the carbon chain is preferentially trans, as this is not hindered by the formation of the intramolecular hydrogen bond. On the other hand, both stereochemical forms of 2,3-BD present a different behavior, as their most stable conformers adopt a gauche arrangement around the CCCC 
TABLE 2: Dihedral Angles, Relative Energies $\left(\Delta E_{0}\right)$, Relative Populations at 298.15 K $(P)$, Total Energies at $298.15 \mathrm{~K}\left(E_{\text {Total }}\right)$, and Dipole Moments $(\mu)$ for the Most Stable Conformers of Butanediols

\begin{tabular}{|c|c|c|c|c|c|c|c|c|c|c|}
\hline \multirow[b]{2}{*}{ molecule } & \multirow[b]{2}{*}{ conformer } & \multicolumn{5}{|c|}{ dihedral angles/deg ${ }^{a}$} & \multirow{2}{*}{$\begin{array}{c}\Delta E_{0} / \\
\mathrm{kJ} \mathrm{mol}^{-1}\end{array}$} & \multirow[b]{2}{*}{$P(\%)$} & \multirow{2}{*}{$\begin{array}{c}-E_{\text {total }}(298.15 \mathrm{~K}) / \\
\text { hartree }\end{array}$} & \multirow[b]{2}{*}{$\mu / \mathrm{D}$} \\
\hline & & $1 \mathrm{st}$ & 2nd & $3 \mathrm{rd}$ & 4th & 5 th & & & & \\
\hline \multirow[t]{21}{*}{ (R)-1,2-BD } & $\mathrm{tG}^{\prime} \mathrm{Tg}$ & 166.0 & -57.5 & -176.2 & 48.7 & & 0.00 & 21.94 & 308.8406285 & 2.49 \\
\hline & $\mathrm{gG}^{\prime} \mathrm{Tt}$ & 51.2 & -58.9 & -178.5 & 162.3 & & 0.69 & 16.58 & 308.8403249 & 2.84 \\
\hline & $\mathrm{g}^{\prime} \mathrm{G}^{\prime} \mathrm{Tg}$ & -76.1 & -54.0 & -177.2 & 40.8 & & 1.64 & 11.32 & 308.8401017 & 2.45 \\
\hline & $\mathrm{gG}^{\prime} \mathrm{Tg}^{\prime}$ & 42.9 & -54.7 & -174.2 & -75.7 & & 3.21 & 6.01 & 308.8395099 & 2.79 \\
\hline & $\mathrm{gG}^{\prime} \mathrm{G}^{\prime} \mathrm{t}$ & 50.5 & -58.7 & -67.4 & 168.6 & & 3.22 & 5.99 & 308.8393968 & 2.93 \\
\hline & $\mathrm{tG}^{\prime} \mathrm{G}^{\prime} \mathrm{g}$ & 168.6 & -57.5 & -67.9 & 47.4 & & 3.37 & 5.62 & 308.8393634 & 2.58 \\
\hline & $\mathrm{g}^{\prime} \mathrm{GTt}$ & -53.9 & 60.0 & 179.4 & -175.1 & & 4.01 & 4.35 & 308.8391468 & 2.69 \\
\hline & $\mathrm{g}^{\prime} \mathrm{GG}^{\prime} \mathrm{t}$ & -54.9 & 62.2 & -66.6 & -168.9 & & 4.42 & 3.68 & 308.8390362 & 2.53 \\
\hline & $\mathrm{tGTg}^{\prime}$ & -165.8 & 59.6 & -176.6 & -49.8 & & 4.72 & 3.27 & 308.8388156 & 2.56 \\
\hline & $\mathrm{g}^{\prime} \mathrm{G}^{\prime} \mathrm{G}^{\prime} \mathrm{g}$ & -77.3 & -54.2 & -69.3 & 40.6 & & 4.85 & 3.09 & 308.8388764 & 2.57 \\
\hline & $\mathrm{tG}^{\prime} \mathrm{Gg}$ & 166.7 & -59.2 & 62.5 & 48.4 & & 4.89 & 3.05 & 308.8388074 & 2.46 \\
\hline & $\mathrm{g}^{\prime} \mathrm{GTg}$ & -46.6 & 56.7 & -177.3 & 76.7 & & 5.24 & 2.65 & 308.8387053 & 2.42 \\
\hline & ${ }^{\circ} G^{\prime} G^{\prime} g^{\prime}$ & 43.1 & -54.3 & -64.9 & -78.6 & & 5.32 & 2.57 & 308.8387068 & 2.90 \\
\hline & $\mathrm{gG}^{\prime} \mathrm{Gt}$ & 52.6 & -61.3 & 60.4 & 163.9 & & 5.76 & 2.15 & 308.8384776 & 2.75 \\
\hline & $\mathrm{gGTg}^{\prime}$ & 77.7 & 55.5 & -176.6 & -41.8 & & 6.35 & 1.69 & 308.8383123 & 2.59 \\
\hline & $\mathrm{tGG}^{\prime} \mathrm{g}^{\prime}$ & -166.1 & 62.0 & -65.1 & -52.6 & & 6.55 & 1.56 & 308.8380992 & 2.48 \\
\hline & $\mathrm{g}^{\prime} \mathrm{G}^{\prime} \mathrm{Gg}$ & -73.7 & -55.7 & 61.8 & 40.6 & & 6.56 & 1.56 & 308.8382759 & 2.39 \\
\hline & $\mathrm{g}^{\prime} \mathrm{GG}^{\prime} \mathrm{g}$ & -47.1 & 58.9 & -64.6 & 72.6 & & 7.02 & 1.29 & 308.8380565 & 2.31 \\
\hline & $\mathrm{gGG}^{\prime} \mathrm{g}^{\prime}$ & 78.2 & 56.8 & -65.8 & -43.6 & & 8.54 & 0.70 & 308.8374209 & 2.73 \\
\hline & $\mathrm{gG}^{\prime} \mathrm{Gg}^{\prime}$ & 44.5 & -56.8 & 62.1 & -75.9 & & 9.25 & 0.53 & 308.8372362 & 2.92 \\
\hline & tTTt & 179.2 & -173.4 & -175.5 & 177.7 & & 9.84 & 0.41 & 308.8365629 & 0.34 \\
\hline \multirow[t]{16}{*}{ (R)-1,3-BD } & $\mathrm{g}^{\prime} \mathrm{GG}^{\prime} \mathrm{t}$ & -47.5 & 73.4 & -57.4 & 176.6 & & 0.00 & 28.56 & 308.8417068 & 3.90 \\
\hline & tGG'g & -175.0 & 60.7 & -70.6 & 43.5 & & 0.37 & 24.55 & 308.8415751 & 3.66 \\
\hline & $\mathrm{gGG}^{\prime} \mathrm{g}$ & 73.4 & 60.6 & -65.9 & 47.8 & & 1.37 & 16.46 & 308.8412404 & 2.92 \\
\hline & $\mathrm{g}^{\prime} \mathrm{GG}^{\prime} \mathrm{g}^{\prime}$ & -51.2 & 68.6 & -57.5 & -76.1 & & 1.89 & 13.34 & 308.8410470 & 3.22 \\
\hline & $\mathrm{tG}^{\prime} \mathrm{G}^{\prime} \mathrm{t}$ & 171.8 & -66.5 & -64.0 & 173.5 & & 5.66 & 2.92 & 308.8390997 & 0.40 \\
\hline & $\mathrm{gG}^{\prime} \mathrm{Gt}$ & 47.2 & -72.3 & 55.2 & -177.1 & & 5.81 & 2.74 & 308.8395092 & 3.92 \\
\hline & $\mathrm{gG}^{\prime} \mathrm{Gg}$ & 49.8 & -66.0 & 59.2 & 69.0 & & 7.08 & 1.64 & 308.8390782 & 2.98 \\
\hline & $\mathrm{tG}^{\prime} \mathrm{Gg}^{\prime}$ & 176.9 & -57.8 & 71.1 & -45.8 & & 7.11 & 1.62 & 308.8390344 & 3.71 \\
\hline & $\mathrm{gG}^{\prime} \mathrm{G}^{\prime} \mathrm{t}$ & 77.2 & -50.8 & -45.7 & -174.5 & & 7.62 & 1.32 & 308.8385762 & 2.67 \\
\hline & $\mathrm{tG}^{\prime} \mathrm{G}^{\prime} \mathrm{g}$ & -173.7 & -49.0 & -46.6 & 75.2 & & 7.71 & 1.27 & 308.8385145 & 2.41 \\
\hline & $\mathrm{g}^{\prime} \mathrm{G}^{\prime} \mathrm{Gg}^{\prime}$ & -72.2 & -58.1 & 66.9 & -52.0 & & 8.24 & 1.03 & 308.8386085 & 2.81 \\
\hline & $\mathrm{g}^{\prime} \mathrm{G}^{\prime} \mathrm{G}^{\prime} \mathrm{g}$ & -66.0 & -49.1 & -47.9 & 74.2 & & 8.27 & 1.02 & 308.8382799 & 2.67 \\
\hline & $\mathrm{tTG}^{\prime} \mathrm{t}$ & -172.5 & -175.4 & -59.4 & -178.0 & & 8.29 & 1.01 & 308.8380580 & 2.15 \\
\hline & $\mathrm{gG}^{\prime} \mathrm{G}^{\prime} \mathrm{g}^{\prime}$ & 77.1 & -52.5 & -46.0 & -69.8 & & 8.45 & 0.95 & 308.8382027 & 2.74 \\
\hline & $\mathrm{g}^{\prime} \mathrm{TG}^{\prime} \mathrm{t}$ & -67.8 & -176.6 & -62.0 & -179.8 & & 8.68 & 0.86 & 308.8379443 & 2.59 \\
\hline & $\mathrm{tTG}^{\prime} \mathrm{g}^{\prime}$ & -176.0 & 179.8 & -59.4 & -67.6 & & 9.11 & 0.72 & 308.8377271 & 0.14 \\
\hline \multirow[t]{11}{*}{$1,4-\mathrm{BD}$} & $\mathrm{g}^{\prime} \mathrm{GG}^{\prime} \mathrm{Gt}$ & -60.9 & 74.3 & -73.6 & 72.8 & 177.7 & 0.00 & 50.84 & 308.8360686 & 3.41 \\
\hline & $\mathrm{g}^{\prime} \mathrm{GG}^{\prime} \mathrm{Gg}$ & -62.7 & 75.8 & -68.7 & 69.9 & 70.7 & 1.53 & 27.40 & 308.8355119 & 3.90 \\
\hline & $t G^{\prime} G^{\prime} g$ & -177.3 & 75.7 & -52.4 & -51.6 & 76.1 & 3.79 & 11.02 & 308.8344645 & 3.79 \\
\hline & $\mathrm{tG}^{\prime} \mathrm{TGt}$ & 178.6 & -62.8 & 180.0 & 62.9 & -178.6 & 5.22 & 3.10 & 308.8332769 & 0.00 \\
\hline & tTTTt & 180.0 & 180.0 & -180.0 & 180.0 & 180.0 & 7.37 & 0.65 & 308.8323011 & 0.00 \\
\hline & tTTGt & -177.8 & -178.5 & -178.7 & 64.9 & -176.9 & 8.07 & 1.96 & 308.8321540 & 2.19 \\
\hline & gTTGt & 58.9 & 177.8 & 179.6 & 63.4 & -179.3 & 8.58 & 1.60 & 308.8320673 & 3.54 \\
\hline & g'TTTg & -62.7 & -177.2 & -180.0 & 177.2 & 62.7 & 8.91 & 0.70 & 308.8318966 & 0.00 \\
\hline & tGTGt & 179.8 & 62.8 & 177.2 & 62.8 & 179.8 & 8.92 & 0.70 & 308.8319667 & 2.32 \\
\hline & tTTGg & -179.7 & -179.4 & -178.2 & 62.3 & 65.2 & 9.36 & 1.17 & 308.8317352 & 3.39 \\
\hline & $\mathrm{gG}^{\prime} \mathrm{GGt}$ & 13.1 & -78.1 & 49.8 & 50.2 & 171.2 & 10.06 & 0.88 & 308.8320182 & 3.01 \\
\hline \multirow[t]{10}{*}{$(R, S)-2,3-\mathrm{BD}$} & $\mathrm{tGg}^{\prime}$ & -169.7 & 59.6 & -51.4 & & & 0.00 & 44.85 & 308.8450209 & 2.53 \\
\hline & $\mathrm{gG}^{\prime} \mathrm{g}^{\prime}$ & 44.0 & -56.8 & -71.8 & & & 1.85 & 21.24 & 308.8445160 & 2.37 \\
\hline & $\mathrm{tG}^{\prime} \mathrm{g}$ & 165.4 & -60.8 & 51.8 & & & 2.58 & 15.85 & 308.8439298 & 2.69 \\
\hline & $\mathrm{g}^{\prime} \mathrm{Gg}$ & -44.2 & 55.9 & 81.1 & & & 4.52 & 7.24 & 308.8433682 & 2.85 \\
\hline & $\mathrm{tTt}$ & -174.1 & 180.0 & 174.1 & & & 5.22 & 2.73 & 308.8427298 & 0.00 \\
\hline & $\mathrm{g}^{\prime} \mathrm{Tt}$ & -80.7 & 179.9 & 170.9 & & & 6.29 & 3.55 & 308.8423464 & 1.87 \\
\hline & $g^{\prime} \mathrm{Tg}$ & -81.3 & -180.0 & 81.4 & & & 7.61 & 1.04 & 308.8418236 & 0.00 \\
\hline & $\mathrm{tTg}^{\prime}$ & 178.8 & 178.0 & -74.4 & & & 7.92 & 1.84 & 308.8417036 & 2.26 \\
\hline & $\mathrm{gTg}^{\prime}$ & 68.6 & -180.0 & -68.6 & & & 8.52 & 0.72 & 308.8415607 & 0.00 \\
\hline & gTg & 69.4 & -179.7 & 72.1 & & & 9.58 & 0.94 & 308.8411558 & 2.45 \\
\hline (S,S)-2,3-BD & $\mathrm{tGg}^{\prime}$ & -168.2 & 54.9 & -46.4 & & & 0.00 & 50.64 & 308.8458325 & 2.80 \\
\hline & $\mathrm{gGg}^{\prime}$ & 80.0 & 50.9 & -39.7 & & & 1.67 & 25.83 & 308.8453398 & 2.79 \\
\hline & $\mathrm{tG}^{\prime} \mathrm{g}$ & 167.9 & -59.0 & 53.2 & & & 3.13 & 14.35 & 308.8446248 & 2.53 \\
\hline & $\mathrm{gG}^{\prime} \mathrm{g}^{\prime}$ & 44.7 & -54.9 & -76.9 & & & 5.10 & 6.47 & 308.8438896 & 2.54 \\
\hline & $\mathrm{gG}^{\prime} \mathrm{g}$ & 82.8 & -59.4 & 82.8 & & & 5.81 & 2.43 & 308.8432402 & 0.44 \\
\hline & $\mathrm{tTt}^{\circ}$ & -179.6 & 171.3 & -179.6 & & & 11.13 & 0.28 & 308.8413891 & 0.32 \\
\hline
\end{tabular}

${ }^{a}$ See Table 1 for dihedral identification.

backbone (see Figure 1). This is explained by specific conformational features that destabilize the otherwise preferred trans conformation around the CCCC backbone. In the $(R, S)$ - form, because of the relative positioning of the two hydroxyl groups, the trans conformation around the CCCC dihedral forbids the formation of the hydrogen bond. In the case of the $(S, S)$ stereoisomer, the gauche arrangement of the carbon chain (A in Figure 2) is also preferred over the trans. This latter 

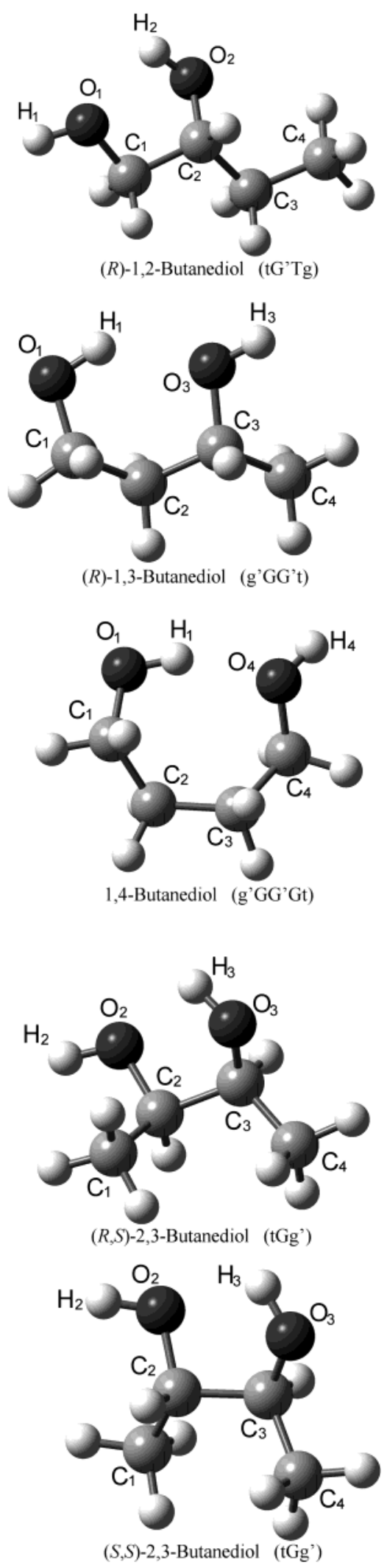

Figure 1. Low-energy conformers of the different butanediol isomers in the gas state optimized at the B3LYP/6-311++(d,p) level of theory. The conformation labels are given in parentheses.

configuration (B in Figure 2) would approach both hydroxyls to the terminal methyl groups, originating two steric repulsions of methyl to hydroxyl groups, whereas in the A configuration there is only one, between the two methyl groups.

In the case of $(R)-1,3-\mathrm{BD}$, the most stable conformers are of the $\mathrm{xGG}^{\prime} \mathrm{x}$ type, where $\mathrm{x}$ can be $\mathrm{g}, \mathrm{g}^{\prime}$, or $\mathrm{t}$. In fact, this backbone
TABLE 3: Hydrogen Bond Parameters for the Lowest Energy Conformers of Each Butanediol Isomer

\begin{tabular}{lccc}
\hline \multicolumn{1}{c}{ isomer } & $\mathrm{O}-\mathrm{H} / \mathrm{pm}$ & $\mathrm{H} \cdots \mathrm{O} / \mathrm{pm}$ & $\mathrm{O}-\mathrm{H} \cdots \mathrm{O} / \mathrm{deg}$ \\
\hline$(R)-1,2-\mathrm{BD}$ & 96.5 & 227.3 & 110 \\
$(R)-1,3-\mathrm{BD}$ & 96.7 & 201.2 & 137 \\
$1,4-\mathrm{BD}$ & 97.0 & 187.4 & 156 \\
$(R, S)-2,3-\mathrm{BD}$ & 96.5 & 228.7 & 109 \\
$(S, S)-2,3-\mathrm{BD}$ & 96.5 & 218.0 & 112
\end{tabular}<smiles>CC1C2CC3CC1C(O)C(C2C)C3O</smiles>

(A)<smiles>CC1C(C)C2C3C(O)CC2(C)CC1C3O</smiles>

(B)
Figure 2. Newman projections of (A) the $\mathrm{tGg}^{\prime}$ (or $\mathrm{gGg}^{\prime}$ ) and (B) $\mathrm{tG}^{\prime} \mathrm{g}$ (or $\mathrm{gG}^{\prime} \mathrm{g}^{\prime}$ ) conformations of $(S, S)-2,3 \mathrm{BD}$, showing the steric repulsion of the more voluminous groups in the second case.

conformation enables the establishment of an intramolecular hydrogen bond without breaking the trans arrangement of the carbon chain. The conformation of the global minimum obtained is very close to the one detected experimentally by conventional microwave spectroscopy. ${ }^{13}$

Finally, for 1,4-BD, the formation of an intramolecular hydrogen-bonded conformation involves the distortion of the carbon chain to a gauche arrangement, which enables the approaching of the two hydroxyl groups. Traetteberg et al. studied the molecular and conformational equilibrium of this molecule by gas-phase electron diffraction (GED) at two different temperatures, 144 and $260{ }^{\circ} \mathrm{C} .{ }^{6}$ These authors found that the whole set of hydrogen-bonded conformations ( $x G^{\prime} G^{\prime} x$ and $\mathrm{xGG}^{\prime} \mathrm{Gx}$, using our conformational nomenclature; see Table 1 for details) are present in a large amount at both temperatures. For both types of backbone conformations, the authors could obtain good fits to the experimental data, but without being able to distinguish between them. These findings are in good agreement with the conformational behavior derived from our DFT calculations, as shown in Table 2.

Besides energy, the dipole moment can also give information on the individual conformers' contributions for the overall isomer mean structure. A variety of values are expected between zero (antiparallel alignment) and a maximum of twice the single dipole moment (parallel alignment). To estimate the contribution of a single hydroxyl group for the total dipole moment, we calculated it for 1-butanol, using the most stable conformer of the isolated molecule as obtained by Ohno et al. ${ }^{29}$ at the HF/ 6-31G level of theory. From this calculation, a value of $2.00 \mathrm{D}$ was obtained. The comparison of this figure with the results obtained for the conformers listed in Table 3 leads to the conclusion that the relative orientation of the $\mathrm{OH}$ groups favors an increase of the electrical dipole moment. From the comparison between isomers, it should be noted that the parallel alignment of the hydroxyl dipoles is more easily attained for $(R)-1,3-\mathrm{BD}$ and 1,4-BD than for $(R)-1,2-\mathrm{BD}$ or 2,3-BD, which is in agreement with the structural features considered above regarding the intramolecular hydrogen bonding.

Determination of the Enthalpies of Butanediols in the Liquid State from the Enthalpies in the Gas State. So far, only structural parameters for the low-energy conformers of each isomer have been considered. From the values of $E_{\text {total }}$ and $P$, the weighted mean energy $\left(E_{\mathrm{gas}}\right)$ and enthalpy $\left(H_{\mathrm{gas}}\right)$ of each isomer in the gas state can be computed from eqs 2 and 3, 
TABLE 4: Calculated Values of the Total Energy in the Gas State $\left(E_{\text {gas }}\right)$ and of the Enthalpy in the Gas State $\left(H_{\text {gas }}\right)$, Experimental Values of the Enthalpy of Vaporization $\left(\Delta H^{\circ}\right.$ vap $)$, Calculated Values of the Enthalpy in the Liquid State $\left(H_{\text {liq }}\right)$ of Butanediols, and Calculated Values of the Enthalpy in the Gas $\left(H_{r g}\right)$ and Liquid $\left(H_{\mathrm{rl}}\right)$ States Relative to $H_{\text {liq }}$ of $(R, S)-2,3-B^{a}$

\begin{tabular}{|c|c|c|c|c|c|c|}
\hline isomer & $-E_{\mathrm{gas}} / \mathrm{kJ} \mathrm{mol}^{-1}$ & $-H_{\mathrm{gas}} / \mathrm{kJ} \mathrm{mol}^{-1}$ & $\Delta H_{\text {vap }}^{\circ} / \mathrm{kJ} \mathrm{mol}^{-1}$ & $-H_{\mathrm{liq}} / \mathrm{kJ} \mathrm{mol}^{-1}$ & $H_{\mathrm{rg}} / \mathrm{kJ} \mathrm{mol}^{-1}$ & $H_{\mathrm{rl}} / \mathrm{kJ} \mathrm{mol}^{-1}$ \\
\hline (R)-1,2-BD & 810858.53 & 810856.05 & 73.3 & 810929.35 & 78.80 & 5.50 \\
\hline (R)-1,3-BD & 810862.06 & 810859.59 & 72.3 & 810931.89 & 75.26 & 2.96 \\
\hline 1,4-BD & 810847.20 & 810844.72 & 78.3 & 810923.02 & 90.13 & 11.83 \\
\hline$(R, S)-2,3-\mathrm{BD}$ & 810870.73 & 810868.25 & 66.6 & 810934.85 & 66.60 & 0.00 \\
\hline$(S, S)-2,3-\mathrm{BD}$ & 810873.42 & 810870.94 & 63.2 & 810934.14 & 63.91 & 0.71 \\
\hline
\end{tabular}

${ }^{a}$ All values refer to $298.15 \mathrm{~K}$.

respectively. The values obtained for these two quantities are inserted in Table 4.

$$
\begin{gathered}
E_{\mathrm{gas}}=\sum P(i) E_{\mathrm{total}}(i) \\
H_{\mathrm{gas}}=E_{\mathrm{gas}}+R T
\end{gathered}
$$

From the enthalpy in the gas state, the enthalpy of butanediols in liquid state $\left(H_{\text {liq }}\right)$ can be estimated provide that values for the enthalpy of vaporization are available $\left(\Delta H^{\circ}\right.$ vap $)$. Therefore, $H_{\text {liq }}$ can be given by

$$
H_{\text {liq }}=H_{\text {gas }}-\Delta H_{\text {vap }}^{\circ}
$$

In a recent work performed in our research group, accurate values for the enthalpy of vaporization of butanediol isomers were obtained, ${ }^{14}$ which were used in this calculation. The enthalpies calculated for liquid butanediols as well as the quantities required for its calculation are also presented in Table 4.

This method of estimation of the enthalpy of a compound in the liquid state using theoretical calculations performed on the isolated molecule is a valuable one, as computational studies in liquids are difficult even for simple molecules as these of butanediols and given the scarceness of reliable data available for these systems.

Comparing the values obtained for $H_{\text {gas }}$ and $H_{\text {liq }}$ among all isomers, $(S, S)-2,3-\mathrm{BD}$ is the isomer that has the smallest enthalpy values, although slightly higher than the $(R, S)$-isomer in the liquid state. As far as $H_{\text {gas }}$ is concerned, and taking this isomer as the reference, we obtain differences of $26,15,11$, and $3 \mathrm{~kJ} \mathrm{~mol}^{-1}$ for 1,4-BD, $(R)-1,2-\mathrm{BD},(R)-1,3-\mathrm{BD}$, and $(R, S)$ $2,3-\mathrm{BD}$, respectively. The same sequence, apart from the minor difference between the 2,3-BD isomers, is observed for $H_{\text {liq }}$, although the differences between the isomers are significantly smaller. This observation indicates that, as far as enthalpy is concerned, the molecular self-association should not affect the molecular conformation in gas state in a substantially different way.

The comparison of the $H_{\text {gas }}$ and $H_{\text {liq }}$ values for the different butanediol isomers raises an important question about the structural interpretation of the enthalpy of vaporization values. The differences between the enthalpy of vaporization of different compounds are commonly ascribed to structural differences in the liquid state. This property is sometimes correlated with the properties of the liquid state. However, this is only valid when the gas molecules have the same enthalpy level. For butanediols, the differences in enthalpy values between each of the isomers in the gas are larger than those in the liquid, and differences in $H_{\text {gas }}$ should be considered in the interpretation of $\Delta H_{\text {vap. }}^{\circ}$.

Infrared Spectroscopy. In an attempt to follow as close as possible the hydrogen bonding involving the butanediol from the isolated molecule to the liquid state, FT-IR spectra were recorded in the $\mathrm{OH}$ stretching region at room temperature for each isomer, in carbon tetrachloride solutions in a concentration range $2.8 \times 10^{-3}-5.5 \times 10^{-2} \mathrm{M}$, as well as for pure liquids.

The butanediols used in the spectroscopic study, supplied by Sigma-Aldrich Co., are of the best grade commercially available. The purity degree specified by the dealer, higher than 0.99 , was tested by gas-liquid chromatography, giving results between 0.991 and 0.998 . The spectra were recorded with a Bomem MB 104 spectrometer using $\mathrm{KBr}$ cells of $1 \mathrm{~mm}$ path length for solutions and $0.1 \mathrm{~mm}$ for the pure liquids. Spectra were collected after 32 scans at $1 \mathrm{~cm}^{-1}$ resolution.

In Figure 3 are presented some spectra for dilute solutions (2.8 mM, bottom spectra), for an intermediate concentration (55.5 mM, middle spectra), and for pure liquids (top spectra) in the $\mathrm{OH}$ stretching region. The spectrum of $(S, S)-2,3-$ butanediol is not shown, as it is very similar to the spectrum of 1,2-butanediol. For a better clarification of the vibrational modes, a band component analysis was performed. The OriginLab Origin 7.0 peak fitting module was used for this purpose. An accurate resolution was achieved by fitting Lorentzian-shaped curves to the higher frequency bands and a Gaussian-shaped curve to the lowest one. Consecutive iterations were performed until a high fitting degree of the component bands to the starting spectra was attained. The mean values obtained for the $\chi^{2}$ adjustment parameter were less than $10^{-6}$.

At low concentrations, all isomers exhibit two absorption bands: the one with the highest frequency corresponds to the $\mathrm{O}-\mathrm{H}$ group undisturbed by hydrogen bond, $\nu \mathrm{OH}_{\text {free}}$, and the other to the $\mathrm{OH}$ group participating in the intramolecular hydrogen bond, $v \mathrm{OH}_{\text {intra. }}$. The intramolecular hydrogen bonding in butanediols has been evidenced by infrared spectroscopy in the vapor phase and in dilute solutions of carbon tetrachloride and carbon disulfide. ${ }^{10}$ Spectroscopic data obtained from matrix isolation studies ${ }^{11}$ generally agree with all of the former, except for 1,4-BD, for which the $v \mathrm{OH}_{\text {intra }}$ band was not observed.

In Table 5, we can find the results obtained for the peak frequency, $v$, and the bandwidth at half-height, $\Delta v_{1 / 2}$, for the two bands at five different concentrations. In the range of concentrations studied, the values of these parameters for each isomer are not concentration dependent.

Among the manifestations of hydrogen bonding in vibrational spectra are the red shift of $\nu \mathrm{OH}$ and the broadening of the stretching vibration band of the hydrogen donor group. The peak frequency shift, $\Delta v=v \mathrm{OH}_{\text {free }}-v \mathrm{OH}_{\text {intra }}$, is commonly used to evaluate the strength of the hydrogen bond, and correlations between this feature and the enthalpy of the hydrogen bond formation have been proposed by several authors. ${ }^{30,31}$ The small frequency differences observed for $\nu \mathrm{OH}_{\text {free }}$ between each isomer should be ascribed to subtle differences in the free hydroxyl group environments, namely, to different conformational arrangements. Since the band assigned to the $\nu \mathrm{OH}_{\text {intra }}$ mode was observed for all isomers, all of them have an intramolecular hydrogen bond, at least in dilute solution. On the grounds of the frequency displacement values $(\Delta v)$, the strengths of the intramolecular hydrogen bonds are ordered as $1,2-\mathrm{BD} \approx 2,3-$ 

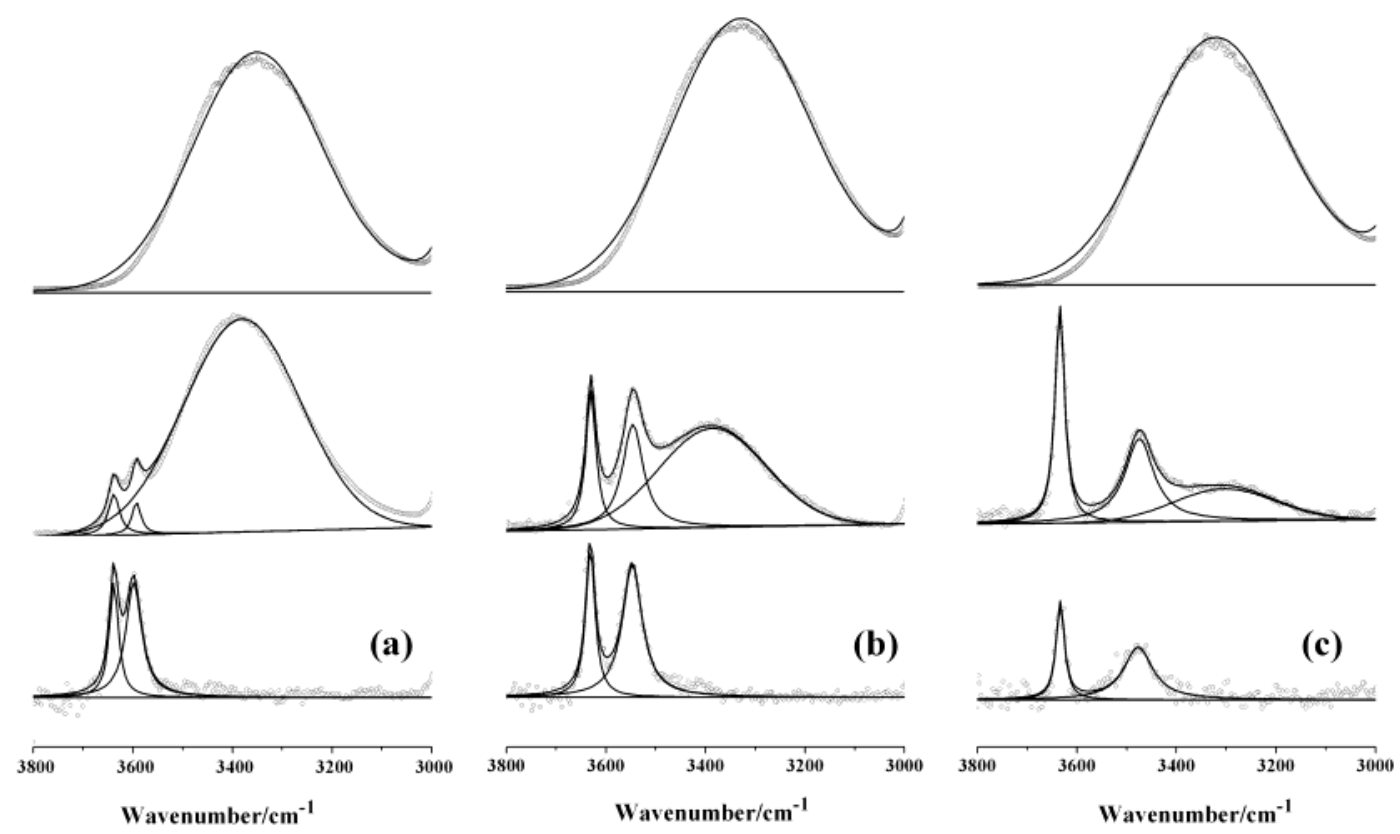

Figure 3. IR spectra and band component analysis of the hydroxyl stretching region of (a) ( \pm )-1,2-butanediol, (b) ( \pm )-1,3-butanediol, and (c) 1,4-butanediol in $2.8 \mathrm{mM} \mathrm{CCl}_{4}$ solutions (bottom spectra), $55.5 \mathrm{mM} \mathrm{CCl}_{4}$ solutions (middle spectra), and pure liquids (top spectra). The spectrum of $(S, S)$-2,3-butanediol is not shown, as it is similar to $( \pm)$-1,2-butanediol. Measured spectra are plotted as open circles; both fitted spectrum and individual bands are shown as solid lines. For improved visualization, each spectrum is differently scaled in the $y$-axis.

TABLE 5: Frequency $(v)$ and Width at Half-Height $\left(v_{1 / 2}\right)$ of the Free and Intramolecular OH Stretching Bands ${ }^{a}$

\begin{tabular}{lccccc}
\hline & \multicolumn{2}{c}{$\mathrm{OH}_{\text {free }}$} & & \multicolumn{2}{c}{$\mathrm{OH}_{\text {intra }}$} \\
\cline { 2 - 3 } \cline { 5 - 6 } isomer & $v / \mathrm{cm}^{-1}$ & $\Delta v_{1 / 2} / \mathrm{cm}^{-1}$ & & $v / \mathrm{cm}^{-1}$ & $\Delta v_{1 / 2} / \mathrm{cm}^{-1}$ \\
\hline$( \pm)-1,2-\mathrm{BD}$ & $3638 \pm 0.7$ & $25 \pm 0.8$ & & $3598 \pm 0.4$ & $36 \pm 2$ \\
$( \pm)-1,3-\mathrm{BD}$ & $3631 \pm 0.7$ & $24 \pm 0.8$ & & $3547 \pm 0.7$ & $49 \pm 1$ \\
1,4-BD & $3634 \pm 0.3$ & $22 \pm 1.0$ & & $3474 \pm 1.0$ & $78 \pm 4$ \\
$(S, S)-2,3-B D$ & $3634 \pm 0.8$ & $17 \pm 1.1$ & & $3588 \pm 0.4$ & $36 \pm 3$
\end{tabular}

a The values reported correspond to the average of five measurements $(n=5)$. Uncertainties are given as the standard deviation.

$\mathrm{BD}<1,3-\mathrm{BD}<1,4-\mathrm{BD}$. This sequence is in agreement with the one based on intramolecular $\mathrm{H} \cdots \mathrm{O}$ distances, shown in Table 3. Indeed, a quantitative relationship is observed between $\Delta v$ and these $\mathrm{H} \cdots \mathrm{O}$ distances, which was fitted to

$$
\ln (\Delta v)=-0.0353(\mathrm{H} \cdots \mathrm{O})+11.62
$$

with $\Delta v$ in $\mathrm{cm}^{-1}$ and the $\mathrm{H} \cdots \mathrm{O}$ distance in $\mathrm{pm}$.

As the concentration reaches a value around $10 \mathrm{mM}$, the intensities of the $\nu \mathrm{OH}_{\text {free }}$ and $\nu \mathrm{OH}_{\text {intra }}$ absorption bands present negative deviations from Beer's law, and a broad band localized at lower frequencies appears (see Figure 3). This band, seen in relatively concentrated solutions, and assigned to the $\mathrm{OH}$ group involved in the intermolecular hydrogen bond, $v \mathrm{OH}_{\text {inter }}$, is an indication of the interaction between the solute molecules involved in a self-association process that originates $n$-mers. The $v \mathrm{OH}_{\text {inter }}$ band, either in carbon tetrachloride solution or in the pure liquid, is fitted by a single Gaussian function. There is nothing in its shape that can suggest a composite character, resulting from overlapped bands from particular hydrogen bond systems. The values for peak frequency, $v$, and the bandwidth at half-height, $\Delta v_{1 / 2}$, for the $\mathrm{OH}$ stretching band for the liquid butanediols are shown in Table 6 .

Because of the cooperativity of hydrogen bonding, ${ }^{32}$ the intermolecular bonds are strengthened as the number of incorporated molecules increases. In fact, a decrease of 70-90 $\mathrm{cm}^{-1}$ can be observed in the peak center between the beginning of the aggregation process in $\mathrm{CCl}_{4}$ and the liquid state.
TABLE 6: Frequency $(v)$ and Width at Half-Height $\left(\Delta v_{1 / 2}\right)$ of the Intermolecular OH Stretching Band for the Pure Liquids

\begin{tabular}{lcc}
\hline isomer & $v / \mathrm{cm}^{-1}$ & $\Delta v_{1 / 2} / \mathrm{cm}^{-1}$ \\
\hline$( \pm)-1,2-\mathrm{BD}$ & 3351 & 303 \\
$( \pm)-1,3-\mathrm{BD}$ & 3328 & 323 \\
$1,4-\mathrm{BD}$ & 3323 & 321 \\
$(S, S)-2,3-\mathrm{BD}$ & 3365 & 293
\end{tabular}

The order of magnitude for the enthalpy of the $\mathrm{O} \cdots \mathrm{H}$ bond can be obtained from the $\nu \mathrm{OH}_{\text {inter }}$ to $\Delta H$ correlation. Iogansen ${ }^{31}$ proposed recently the following relationship between the stretching frequency shift and the enthalpy:

$$
\Delta H=-1.92(\Delta v-40)^{1 / 2}
$$

with $\Delta H$ in $\mathrm{kJ} \mathrm{mol}^{-1}$ and $\Delta v$ in $\mathrm{cm}^{-1}$. Applying this relationship to our spectra, values between $29 \mathrm{~kJ} \mathrm{~mol}^{-1}$ for $(S, S)-2,3-\mathrm{BD}$ and $32 \mathrm{~kJ} \mathrm{~mol}^{-1}$ for 1,4-BD are obtained. Theses figures are of the same order of magnitude of that estimated for 1,2-alkanediols with a chain of six or fewer carbon atoms. ${ }^{33}$

It is worth comparing the strength of the intermolecular $\mathrm{H} \cdots \mathrm{O}$ bond between the isomers, as it follows an identical sequence as observed for the $\mathrm{H} \cdots \mathrm{O}$ intramolecular bond in the isolated molecules, although with smaller differences in the first case. A similar trend is observed for the enthalpy, as its values also indicate that the energy differences between liquid isomers are smaller than between isomers of isolated molecules.

\section{Conclusions}

Although the structural characteristics of the butanediol isomers remain similar, we observed that the energy differences between the butanediol isomers are more pronounced in the gas than in the liquid state. Thus, the energy of the gaseous state $\left(H_{\mathrm{gas}}\right)$ should be considered, and special care should be taken for a reasonable interpretation of the value of this thermodynamic function, in which the gas is the reference state.

In this study, we estimated the enthalpy of the liquid state from the combination of high-level calculations for the mol- 
ecules in the gas state and experimental calorimetry vaporization data, which allowed us to determine an important thermodynamic property, $H_{\text {liq }}$, which is quite difficult to estimate with different methods.

Hydrogen bonding is the determinant structural stabilizing factor for butanediols in either gas or liquid states. The values of $\Delta v$ indicate that, along the process of molecular selfassociation, the relative balance between intra- and intermolecular hydrogen bonds tends to shift in favor of the latter ones. However, we found some evidence that the structural features of the molecules in the liquid are of the same nature as those in the gas state and that the intramolecular hydrogen-bonding systems persist in the condensed state.

A good agreement was found among the methods used in our study, since the conclusions derived from the calculations combined with experimental calorimetric data were confirmed by infrared spectroscopy in the hydroxyl stretching region.

Acknowledgment. The authors acknowledge Fundação para a Ciência e a Tecnologia (FCT), Lisbon, for financial support (research project PRAXIS QUI/10137/98).

\section{References and Notes}

(1) Boutron, P.; Mehl, P.; Kaufmann, A.; Angibaud, P. Cryobiology 1986, 23, 453.

(2) Mehl, P.; Boutron, P. Cryobiology 1988, 25, 44.

(3) Boutron, P. Cryobiology 1990, 27, 55.

(4) Sutton, R. L. J. Chem. Soc., Faraday Trans. 1991, 87, 101

(5) Duin, M. V.; Baas, J. M. A.; Graaf, B. V. J. Org. Chem. 1986, 51 1298.

(6) Traetteberg, M.; Hedberg, K. J. Am. Chem. Soc. 1994, 116, 1382

(7) Hasanein, A. A.; Kovac, S. J. Mol. Struct. 1974, 22, 457.

(8) Szarecka, A.; Hoffmann, M.; Rychlewski, J.; Rychlewska, U. J. Mol. Struct. 1996, 374, 363.

(9) Wang, F.; Polavarapu, P. L. J. Phys. Chem. A 2001, 105, 6991.

(10) Fishman, E.; Chen, T. L. Spectrochim. Acta, Part A 1969, 25, 1231. 671

(11) Coleman, W. M., III; Gordon, B. M. Appl. Spectrosc. 1988, 42
(12) Nakao, Y.; Sugeta, H.; Kyogoku, Y. Spectrochim. Acta, Part A 1986, 42, 251

(13) Caminati, W.; Corbelli, G. J. Mol. Struct. 1982, 78, 197.

(14) Eusébio, M. E.; Jesus, A. J.; Cruz, M. C.; Leitão, M. L. P.; Redinha, J. S. J. Chem. Thermodyn., in press.

(15) Donalski, E. S.; Hearing, E. D. J. Phys. Chem. Ref. Data 1993, 22,804

(16) Cerius2 (version 3.5), Molecular Simulations Inc., San Diego, CA, 1997.

(17) Maple, J. R.; Dinur, U.; Hagler, A. T. Proc. Natl. Acad. Sci. U.S.A. 1988, 85, 5350 .

(18) Hwang, M. J.; Stockfish, T. P.; Hagler, A. T. J. Am. Chem. Soc. 1994, $116,2515$.

(19) Hohenberg, P.; Kohn, W. Phys. Rev. B 1964, 136, 864.

(20) Kohn, W.; Sham, L. J. Phys. Rev. A 1965, 140, 1133.

(21) Becke, A. D. J. Chem. Phys. 1993, 98, 5648

(22) Becke, A. D. Phys. Rev. A 1988, 38, 3098.

(23) Lee, C.; Yang, W.; Parr, R. G. Phys. Rev. B 1988, 37, 785.

(24) Frisch, M. J.; Trucks, G. W.; Schlegel, H. B.; Scuseria, G. E.; Robb, M. A.; Cheeseman, J. R.; Zakrzewski, V. G.; Montgomery, J. A., Jr.; Stratmann, R. E.; Burant, J. C.; Dapprich, S.; Millam, J. M.; Daniels, A. D.; Kudin, K. N.; Strain, M. C.; Farkas, O.; Tomasi, J.; Barone, V.; Cossi, M.; Cammi, R.; Mennucci, B.; Pomelli, C.; Adamo, C.; Clifford, S.; Ochterski, J.; Petersson, G. A.; Ayala, P. Y.; Cui, Q.; Morokuma, K.; Malick, D. K.; Rabuck, A. D.; Raghavachari, K.; Foresman, J. B.; Cioslowski, J.; Ortiz, J. V.; Stefanov, B. B.; Liu, G.; Liashenko, A.; Piskorz, P.; Komaromi, I.; Gomperts, R.; Martin, R. L.; Fox, D. J.; Keith, T.; Al-Laham, M. A.; Peng, C. Y.; Nanayakkara, A.; Gonzalez, C.; Challacombe, M.; Gill, P. M. W.; Johnson, B.; Chen, W.; Wong, M. W.; Andres, J. L.; Gonzalez, C.; Head-Gordon, M.; Replogle, E. S.; Pople, J. A. Gaussian 98, revision A.9; Gaussian, Inc.: Pittsburgh, PA, 1998.

(25) Ceccarelli, C.; Jeffrey, G. A.; Taylor, R. J. Mol. Struct. 1981, 70 255

(26) Steiner, Th.; Saenger, W. Acta Crystallogr., Sect. B 1992, 48, 551.

(27) Reiling, S.; Brickmann, J. J. Comput. Chem. 1996, 17, 133.

(28) Vázquez, S.; Mosquera, R. A.; Rios, M. A.; Alsenoy, C. V. J. Mol. Struct. (THEOCHEM) 1988, 181, 149.

(29) Ohno, K.; Yoshida, H.; Watanabe, H.; Fujita, T.; Matsuura, H. J. Phys. Chem. 1994, 98, 6924.

(30) Rozenberg, M. Sh. Spectrochim. Acta, Part A 1996, 52, 1559.

(31) Iogansen, A. V. Spectrochim. Acta, Part A 1999, 55, 1585. 3200 .

(32) Kleeberg, H.; Klein, D.; Luck, W. A. P. J. Phys. Chem. 1987, 91,

(33) Knauth, P.; Sabbah, R. J. Chem. Thermodyn. 1989, 21, 203. 